\title{
Pedagogía de la memoria y educación para el "nunca más" para la construcción de la democracia
}

\author{
Pedagogy of the Memory and Educating for the \\ "Never More" in Order to Build Democracy
}

Susana Sacavino ${ }^{1}$

\section{Resumen}

La educación en derechos humanos es una mediación importante para la afirmación y la construcción de la democracia. En Brasil, en 2014, se cumplieron cincuenta años del golpe civil-militar que dio inicio a una larga dictadura de más de dos décadas, con prácticas sistemáticas de violación de los derechos humanos por parte del Estado. En este contexto es de fundamental importancia desarrollar una pedagogía de la memoria para educar para el nunca más en la línea de la cualificación y mejoramiento de la democracia. Desde un enfoque de (des)conmemoración del cincuentenario de la dictadura civil-militar, este artículo se estructura en tres partes. En la primera, se presenta el origen de la expresión nunca más, su incorporación en la educación en derechos humanos y su relación con la memoria. Se profundiza también en diferentes sentidos de la memoria y sus contribuciones y articulaciones para la educación para el nunca más. Por último, se argumenta sobre por qué educar para el nunca más. En la segunda parte se presentan tres propuestas pedagógicas desde una óptica de (des)conmemoración de los cincuenta años de la dictadura civil-militar para educar para el nunca más: una propuesta de carácter general, otra orientada a la formación de los docentes, y la tercera, para que el maestro pueda trabajar con sus alumnos en el aula de clase. Luego, se tejen algunas consideraciones sobre el tema del trabajo de la(s) memoria(s) y la educación para el nunca más.

\section{Palabras clave}

Educación en derechos humanos; memoria y derechos humanos; formación para la democracia; formación de maestros; educación para el nunca más.

Abstract

The education in human rights is an important mediation for affirming and building democracy. In Brazil, the year of 2014 is the 50th anniversary of the civil-military putsch which had started a long period of dictatorship that lasted more than two decades, with systematic practices of human rights violations by part of the State. Into this framework it is very important to develop a pedagogy of memory to educate for the "never more" in the sense of qualifying and improving the democracy. From the focus on (dis)celebrating the 50th anniversary of the civil-military dictatorship, this article is structured into three parts. The first one presents the origin of the expression "never more", its incorporation by the human rights education, and its relationship with the memory. It also deepens into the different senses of the memory and its contributions and articulations to the education for "never more". Finally it argues why to educate for the "never more". The second part presents three pedagogical proposals from the vision of the (dis)celebrating of the 50 years of the civil-military dictatorship for educating for the "never more": one general character proposal, another guided to the teacher training, and the third one for the teacher to work with their students in class. Finally, some considerations are made about the subject of the work of memory/ies and the education for the "never more".

\section{Keywords}

Human rights education; memory and human rights; training for democracy; teacher training; education for the never more.

\section{Artículo recibido el 27 de octubre de 2014 - aprobado el 19 de noviembre de 2014}

1 Novamerica-Grupo de Estudios sobre Cotidiano, Educación y Cultura/s (GECEC) vinculado al Departamento de Educación de la Pontificia Universidad Católica de Río de Janeiro (PUC-Río). Correo electrónico: s.sacavino@novamerica.org.br 


\section{Introducción}

La educación en derechos humanos es una mediación importante para la afirmación y la construcción de democracia. Comienza a ser desarrollada en América Latina a mediados de la década de 1980, después de las crueles experiencias en varios países de dictaduras civiles-militares, con prácticas sistemáticas de violación de los derechos humanos por parte del Estado.

En la medida en que el Estado durante esos periodos utilizó la violencia, la represión, la tortura, el secuestro, la censura, la persecución, la opresión, las desapariciones y asesinatos como prácticas y políticas del propio Estado, retomar esos marcos de la memoria es de fundamental importancia para afirmar la democracia en el presente y cualificarla para el futuro. No estamos hablando solo del pasado, sino potencialmente de qué forma queremos dar sentido al presente y al futuro, en la construcción y afirmación de sociedades democráticas con una ciudadanía activa, inclusiva y participativa.

Mientras que en los países del Cono Sur al terminar los periodos de dictadura militar enseguida nombraron comisiones para investigar los horrores y las violaciones de los derechos humanos por parte del Estado durante esos gobiernos, en Brasil recién fue posible, en 2012, instalar la Comisión de la Verdad que realizó su trabajo y elaboró un informe para finales de 2014. Esta instalación se dio con muchas resistencias por parte de los sectores de las Fuerzas Armadas y por los grupos sociales conservadores. También, en 2014 se cumplieron cincuenta años del golpe civil-militar que dio inicio a una larga dictadura de más de dos décadas en el país.

Como señala Jelin (2004, p. 142), a medida que pasa el tiempo y se torna posible una distancia temporal entre el pasado y el presente, interpretaciones contrapuestas y a menudo rivales sobre el pasado reciente y sus memorias se instalan en el centro del debate político y cultural, convirtiéndose en cuestiones públicas ineludibles del proceso de democratización. Y en ese sentido un punto de entrada para abordar el tema es el espacio de las luchas acerca del sentido de ciertas fechas y prácticas conmemorativas.
Para hacer presente ese cincuentenario actualizando la memoria, desde diferentes ámbitos de la sociedad civil, instituciones y movimientos sociales, se impulsó y se convocó una (des)conmemoración del cincuentenario. Este término no es apenas un juego de palabras, al contrario, es una síntesis política alternativa que va mucho más allá del lenguaje en sí, porque es la respuesta semántica reivindicativa al derecho a la memoria como respuesta a cualquier intención de reivindicación de la efeméride de los cincuenta años del golpe civil-militar. En este sentido, (des)conmemorar es la contraefeméride es el marco de la memoria plural e irrestricta que apela a nuevos conceptos, para educar para el nunca más y afirmar los derechos humanos para todos los ciudadanos y ciudadanas.

Solo es posible construir un país democrático si (des)conmemoramos y denunciamos los sentidos opresivos de la dictadura civil-militar y los relacionamos con los dramas actuales de violencias, racismo, homofobia, machismo, discriminación y tantas otras formas de exclusión y autoritarismo presentes en la sociedad actual, que frenan y minan la construcción de la democracia. En este sentido, (des)conmemorar el marco de la dictadura es luchar por la memoria pública y sus sentidos en el presente para transformar el futuro.

Pero (des)conmemorar implica también desarrollar procesos de educación en derechos humanos que contribuyan a la promoción de una cultura permeada por ellos que cualifique y fortalezca la democracia y la construcción de la ciudadanía.

Este texto está estructurado en tres partes. En la primera presentamos el origen de la expresión nunca más y su incorporación en la educación en derechos humanos. Profundizamos también en diferentes sentidos de la memoria y sus contribuciones y articulaciones para la educación para el nunca más, para finalmente argumentar por qué educar para el nunca más. En la segunda parte del artículo presentamos tres propuestas pedagógicas para educar para el nunca más desde una óptica de (des)conmemoración de los cincuenta años de la dictadura civilmilitar en nuestro país. Una propuesta de carácter 
general, otra orientada a la formación de los docentes, y la tercera, a que el maestro pueda trabajar con sus alumnos en el aula de clase. Finalizamos el texto tejiendo algunas consideraciones que reafirman la importancia del trabajo de la(s) memoria(s) para la educación para el nunca más.

\section{El origen de un término: nunca más}

El nunca más alude a las consignas utilizadas por los movimientos de derechos humanos en el Cono Sur. Los informes de recopilación de informaciones y listados de violaciones a los derechos humanos por el terrorismo de Estado, elaborados por la Comisión Nacional sobre la Desaparición de Personas (Conadep) en Argentina en 1984, y por organizaciones de derechos en humanos en Brasil en 1985 y en Uruguay, llevan por título nunca más.

Esta expresión fue reafirmada y comenzó a ser incorporada a la lucha contra los horrores de la dictadura por los grupos de derechos humanos, a partir del discurso de acusación del fiscal Julio Strassera en el juicio a las juntas militares en Argentina en 1985, en el que concluye: "Señores jueces: quiero renunciar expresamente a toda pretensión de originalidad para cerrar esta requisitoria. Quiero utilizar una frase que no me pertenece, porque pertenece ya a todo el pueblo argentino. Señores jueces: ¡nunca más!"(Serpaj, 1989, p. 1).

A partir de esos informes, el nunca más se incorpora en los diferentes países como un grito y una consigna de la lucha contra las violaciones sistemáticas de los derechos humanos cometidas por el Estado durante las dictaduras militares. Para los defensores de los derechos humanos, el nunca más involucra tanto un esclarecimiento completo de lo sucedido bajo las dictaduras como el correspondiente castigo a los responsables de las violaciones de los derechos.

En la educación en derechos humanos, esta categoría se incorpora al final de la década de los años 1990. En el Seminario de Análisis de Experiencias de Educación en Derechos Humanos en América Latina, promovido por el Instituto Interamericano de Derechos Humanos, con sede en Costa Rica, y realizado en Lima (Perú) en noviembre de 1999, un grupo de especialistas e investigadores del continente lanzó y defendió la tesis de que para que la construcción democrática continuara avanzando, la educación en derechos humanos requería de impulso. Esta postura exigía que se afirmaran, dentro de los diferentes ámbitos educativos, los siguientes elementos: la visión integral de los derechos; una educación para el nunca más; la puesta en marcha de procesos dirigidos a la formación de sujetos de derecho y de actores sociales; y la promoción del empoderamiento individual y colectivo, especialmente el de los grupos sociales marginados o víctimas de discriminación (Candau, 2005, pp. 7-8).

El primer aspecto señalado entiende los derechos en su globalidad e interdependencia, contrariamente a lo que ocurre en los contextos neoliberales en los que los mismos se reducen a los derechos individuales, políticos y civiles. La comprensión y exigencia de los derechos económicos, sociales y culturales es fundamental para la construcción democrática, así como la de los derechos relacionados con el medio ambiente, el desarrollo de las ciencias de la vida y de las nuevas tecnologías.

La educación para el nunca más, el segundo elemento destacado, promueve el sentido histórico, la importancia de la memoria en lugar del olvido. Supone romper la cultura del silencio, de la invisibilidad y de la impunidad presente en la mayoría de los países latinoamericanos, lo cual es un aspecto fundamental para la educación, la participación, la transformación y el desarrollo de la democracia. Exige mantener siempre viva la memoria de los horrores de las dictaduras, autoritarismos, persecuciones políticas, torturas, desapariciones, exilios y muchas más violaciones de los derechos humanos. Implica saber releer la historia con otros instrumentos y miradas, capaces de despertar energías de coraje, justicia, verdad, esperanza y compromiso que impulsen la construcción y el ejercicio de la ciudadanía (Sacavino, 2000, p. 44).

En ese momento, a finales de la década del noventa, la educación para el nunca más subrayó aspectos orientados a cuestionar, denunciar y exigir memoria, verdad y justicia por todas las viola- 
ciones de los derechos humanos, cometidas en los diferentes países latinoamericanos en los periodos de dictaduras civiles-militares en las décadas anteriores, y en ese sentido, como un eje importante para la construcción democrática. A partir de ahí comienza a ser utilizada la expresión nunca más como un aspecto destacado para la educación en derechos humanos.

Posteriormente, en Chile, en 2004, esta referencia también se refuerza cuando el entonces presidente de la República, Ricardo Lagos, da a conocer al país el Informe de la Comisión Nacional sobre Prisión Política y Tortura que recoge el testimonio de más de 35.000 chilenos que sufrieron detenciones y apremios ilegítimos entre 1973 y 1990. En esa ocasión, Lagos (2004) termina su discurso afirmando: "Porque hemos sido capaces de mirar toda la verdad de frente, podemos empezar a superar el dolor, a restaurar las heridas. Para 'nunca más' vivirlo, 'nunca más' negarlo" (p. 5).

Actualmente podemos afirmar que educar para el nunca más continúa siendo una dimensión importante en nuestra concepción de la educación en derechos humanos para profundizar y mejorar la calidad de nuestras democracias. Pensamos que en las sociedades latinoamericanas construidas históricamente desde el punto de vista social, económico, cultural y político asentadas en la óptica y la lógica de la exclusión del otro, el diferente, el nunca más tiene que ampliarse y, además de considerar las violaciones de los derechos humanos en los periodos de dictaduras, se deben incluir también los enfoques históricos que continúan todavía estando presentes y violando los derechos humanos. En ese sentido, nos referimos a nunca más esclavitud, genocidios, discriminaciones, exclusiones, invisibilizaciones, exterminios, subalternizaciones. Dentro de esa concepción y en esa dirección podemos afirmar que en el momento presente el educar para el nunca más se convirtió en una categoría fuerte dentro de la educación en derechos humanos para la construcción de una cultura democrática.

El tercer elemento destacado en relación con la educación en derechos humanos se refiere a la for- mación de sujetos de derechos, para la cual se hace necesario articular la dimensión ética con la político-social y con las prácticas concretas. Ser sujeto de derechos implica reforzar en la vida cotidiana la lógica expansiva de la democracia, afirmar el principio y el derecho de la igualdad, establecidos en la esfera jurídica y política, y hacer extensiva esa dinámica igualitaria a las diversas esferas de la sociedad. Formar la conciencia de ser sujeto de derechos significa también poder desenvolver, en la práctica y en la construcción de la ciudadanía, la articulación de los derechos de igualdad con los de la diferencia, así como los derechos individuales con los derechos colectivos.

El cuarto elemento, ya señalado, consiste en una educación que promueva el empoderamiento individual y colectivo, sobre todo de los grupos sociales desfavorecidos o discriminados. Esa perspectiva supone potencializar grupos o personas que históricamente han tenido menos poder en la sociedad y que se encuentran dominados, sometidos, excluidos, subalternizados o silenciados en la vida cotidiana y en los procesos sociales, políticos, económicos y culturales. El empoderamiento presenta dos dimensiones básicas que están íntimamente relacionadas. Esas dimensiones son la personal y la social, y la educación en derechos humanos debe promoverlas, afirmarlas y desarrollarlas.

Se apuesta para que esta perspectiva de educación en derechos humanos a partir de la articulación de los cuatro aspectos ejes mencionados: visión integral de los derechos, educación para el nunca más, formación de sujetos de derechos y empoderamiento de los grupos excluidos o subalternizados contribuya para la afirmación de la democracia y para el desenvolvimiento de capacidades que permitan el ejercicio de la ciudadanía y la construcción de la memoria histórica. Todo ello implica saber que esa construcción de la memoria forma parte de las luchas políticas, de manera que varía dependiendo de los momentos históricos de que se trate, y que hay diferentes formas de renovar la memoria para las nuevas generaciones, esas que están hoy muy distantes de los hechos que ella evoca (Stern, 2013, p. 6). 


\section{Educación para el nunca más y memoria(s)}

Las memorias -en plural porque son muchas y diferentes- son una construcción. No se encuentran constituidas de una vez y para siempre, sino que se erigen o se moldean al compás de intereses y significados actuales. Al revés de lo que muchas veces creemos, la memoria no es simplemente la capacidad de traer a la conciencia algo que nos ocurrió, sino la capacidad de integrarlo u organizarlo en una serie de eventos unidos por un cierto significado (Peña, 2013, p. 8). O como nos recuerda Tizon (2012) cuando afirma: "[...] de eso trata la memoria: de reconstruir las huellas para leer en ellas, como en un mapa, cómo llegamos a ser quienes somos en este presente" (p. 6).

Según Rubio (2007, p. 3), la consideración de la memoria como propuesta reflexiva que pueda promover una educación transformadora, se apoya en diferentes fundamentos históricos y epistemológicos.

Un primer aspecto es el reconocimiento de los sujetos como seres históricos, insertos en el tiempo presente, e instados a enfrentar procesos de transformación y coyunturas existenciales que se ven afectadas por una historia heredada pero no estática, que continúa siendo construida. De esta manera, estamos marcados por la historia, pero también dejamos marcas en nosotros mismos mediante la historia que vamos creando. La historia construida por la sociedad, presente en la memoria histórica, muestra tensiones desde sus diferentes sentidos y proyecciones. La relación entre la acción histórica por ser construida y el pasado que recibimos de otros, es decir, aquel que nosotros no hicimos, es lo que preserva la relación dialéctica entre el horizonte de espera y el espacio de experiencia, pudiendo en cada momento configurar una memoria viva temporalizada, siempre emergente, con capacidad de construir el futuro.

Otro aspecto importante que se debe tener presente es la historicidad de la configuración de nuestras sociedades desde la óptica de los derechos humanos. Esta dimensión nos obliga a cuestionar su proyección en el futuro y los valores en los que fue construido el tejido social que se encuentra marcado por situaciones de esclavitud, tortura, eliminación real y simbólica del otro -lo diferente a mí-, persecuciones, desapariciones, desigualdades y, sobre todo, por la violación sistemática de los derechos humanos por parte del Estado durante las dictaduras militares. Todas esas experiencias y acontecimientos implican una ruptura en nuestra vivencia del tiempo, separándolo en un antes y un después, entre el pasado y un futuro que puede ser angustiante e incómodo, pero que también puede desafiarnos como sujetos para la construcción de un futuro diferente, asentado en otros valores orientados por la vigencia y la efectividad de los derechos humanos.

La tercera dimensión que destacamos se refiere a la relación entre memoria y construcción de la interculturalidad. En las sociedades actuales globalizadas y marcadas por las políticas neoliberales, los trabajos en torno a la memoria son importantes para la afirmación de la interculturalidad, lo que demanda políticas de reconocimiento de los diversos grupos socioculturales, además de políticas de redistribución y de representación. Tres procesos en los que la memoria interviene para la construcción de subjetividades colectivas, tal como nos lo recuerda Ricœur: recordar es recordar con los otros (Rubio, 2007, p. 5).

Una educación en derechos humanos que promueva el nunca más debe estimular procesos de trabajo en torno a la memoria y mirar la historia desde la óptica y el ángulo de los vencidos y muchas veces invisibilizados, aquella forjada por las prácticas de los movimientos sociales populares, por los diferentes grupos discriminados y subalternizados, por sus luchas por el reconocimiento y la conquista de sus derechos y ciudadanía en la vida cotidiana, sus resistencias y su insistencia en producir otras maneras de ser, otras sensibilidades, otras percepciones para construir ciudadanía (Sacavino, 2000, p. 45).

\section{Diferentes sentidos de la memoria}

La memoria es un proceso subjetivo que se moviliza a partir de las diversas experiencias materiales, simbólicas y afectivas, que construye un sentido de 
pertenencia y de autoafirmación individual y colectiva en la sociedad. El pasado adquiere sentido en la medida en que se evoca desde el presente con miras al futuro, y con un fin determinado.

No siempre la memoria surge espontáneamente. Muchas veces es necesario intervenir para que se haga presente y para que pueda ser codificada a través de una narrativa.

Las experiencias y vivencias propias o de otras personas y grupos que se interrelacionan para ser recordadas, son elementos importantes de la memoria. Esta también se apoya en las expectativas con relación a la construcción del futuro. En ese sentido, es importante percibir de qué manera el pasado puede iluminar ese camino, así como las experiencias del pasado pueden, en el presente, contribuir de una manera dinámica y creativa para la transformación social.

En la óptica de la educación en derechos humanos es importante iluminar esa transformación desde el nunca más, para que las violaciones a los derechos humanos que se cometieron no vuelvan a repetirse, y para que la transformación sea orientada por la óptica y los valores de la afirmación y efectividad de los derechos.

Puede ser iluminador en el proceso de educación para el nunca más tener presente algunas funciones y dimensiones de la memoria que la cualifican y ayudan a orientar los procesos educativos. Por eso las enumeramos enseguida sin tener la pretensión de abarcarlas todas:

Funciones de la memoria: ayuda a superar, a partir de la toma de distancia, hechos y acontecimientos traumáticos, de olvidos, invisibilizaciones, abusos políticos, etc. También ayuda a promover el debate y la reflexión activa sobre el pasado y sobre su sentido para el presente y para el futuro.

El trabajo en torno a la memoria también posibilita el diálogo entre diferentes grupos de la sociedad, integrando los protagonistas de los conflictos en un mismo escenario de acción para la construcción o reconstrucción de la verdad o verdades en conflicto con el objetivo de promover la justicia y mejorar la calidad de la democracia.
Memoria e identidad: estos dos polos tienen una relación intrínseca en la construcción de la subjetividad. La identidad se va construyendo a partir de lo que hacemos y de lo que somos, así como de lo que cambiamos y las proyecciones futuras que realizamos. También cuando recordamos seleccionamos determinados hechos, acontecimientos, experiencias que sirven para identificarnos con unos y para distanciarnos de otros.

Memoria individual: es una experiencia individual y subjetiva. Recordamos cuando traemos a la memoria acontecimientos pasados, que nos posibilitan actualizar informaciones o impresiones que pueden ser compartidas a través de la palabra, del relato. Más que de un recuerdo, se trata de una reconstrucción (Berro et al., 2010, p. 12).

Memoria social: se expresa mediante un conjunto estructurado de recuerdos compartidos socialmente, y que entidades colectivas con identidad propia conservan suficientemente en el tiempo. La memoria social sobrepasa la suma de las memorias individuales. Es por eso que puede hablarse de comunidades de memoria, en las que lo relevante es el recuerdo de los triunfos, de las conquistas y los traumas. Y es en el contexto de los traumas en donde se sitúan las víctimas. Esta memoria social incluye los recuerdos de los otros y esto presupone una acogida empática y solidaria de las víctimas. A su vez, esto lleva a hacer efectiva la afirmación: $s u$ memoria es la mía (Etxeberria, 2013, p. 18).

Memoria y olvido: la memoria no se opone al olvido. La restitución del pasado es imposible porque la memoria siempre implica una selección. Ciertos trazos de los acontecimientos vividos se conservan; otros son dejados de lado, marginados de inmediato o poco a poco, y con el tiempo, olvidados (Todorov, 2013, p. 18). En los procesos de construcción democrática, los trabajos en torno a la memoria como espacio de reconstrucción del pasado son un derecho legítimo que todas las sociedades poseen.

Memoria y narrativa: la memoria es una narrativa que reconstruye el pasado desde una perspectiva social, cultural y política, al tiempo que crea un nexo entre el pasado y el presente (Berro et al., 2010, p. 13). 
Memoria e historia: la historia entendida como memoria, como una acumulación de representaciones del pasado que los grupos construyen para alimentar el sentido de su vida individual y colectiva, es una preocupación actual para enfrentar las dificultades, los desafíos, las ansiedades del presente, mirando hacia el pasado común (Torres, 2014, p. 45).

Memoria y verdad: el término verdad puede ser resignificado en los trabajos acerca de la memoria. Puede adquirir un nuevo sentido y ampliar la reconstrucción de los acontecimientos y hechos desde otro ángulo, mostrando no solo una verdad de adecuación, de correspondencia exacta entre el discurso actual y los hechos pasados, sino también una verdad de revelación que permite capturar el sentido de los acontecimientos (Todorov, 2013, p. 24).

En América Latina los contornos del derecho a la verdad aún no se encuentran claramente delineados, pero existe un consenso mínimo que sostiene -sea como deducción de otros derechos fundamentales, o como evolución de las prácticas internacionalesque es posible hablar de un principio emergente que reconoce el derecho de las víctimas de las más graves violaciones, de conocer las circunstancias y responsabilidades de los crímenes que sufrieron (González, 2011, p. 348).

Memoria literal y memoria ejemplar: la memoria literal interpreta los hechos del pasado como si fueran algo insuperable e imposible de ser transmitido, con lo cual la acción del presente y las perspectivas del futuro quedan sometidas al pasado. Debido a la imposibilidad de resignificar la experiencia, no da lugar a que ocurra un compromiso social y, con esto, se convierte en una tarea para pocos. En contraposición con esta, la memoria ejemplar interpreta los hechos del pasado como una categoría más general, lo que permite comprender nuevas situaciones. Resignifica la experiencia despojándola de sus características singulares y únicas, para que la memoria se vuelva más productiva. Es, por lo tanto, una tarea de todos y apunta hacia el futuro (Berro et al., 2010, p. 14).

En la educación en derechos humanos es importante trabajar estos aspectos y funciones de la memo- ria, no solo para favorecer la madurez emocional y el desarrollo de la sensibilidad, sino también para favorecer el conocimiento y la apropiación de la historia individual y colectiva. Esto porque, como ya expresamos, hacer memoria es dejar en evidencia los registros de cómo fueron vividos los acontecimientos, los cuales nunca podrán ser una réplica, siempre serán una interpretación. Educar en derechos humanos implica vivir y procesar dicha experiencia por medio de narrativas que denuncian, previenen y ayudan a tomar conciencia para que las violaciones a los derechos humanos no se repitan nunca más.

\section{Por qué educar para el nunca más}

La memoria es un bien público que se encuentra en la base del proceso de construcción de la identidad social, política y cultural de un país. Esto significa que la memoria es fundamental para la construcción de la(s) verdad(es) sobre los acontecimientos históricos, para que no terminen en el olvido y para que nunca más ocurran violaciones sistemáticas de los derechos humanos. En este ítem señalaremos algunos aspectos y dimensiones importantes de la educación para el nunca más, que contribuyen a profundizar y calificar los procesos democráticos.

El primer aspecto es la reflexión crítica sobre la violación de los derechos humanos durante la dictadura militar, con el fin de crear una conciencia colectiva para que esas situaciones no vuelvan a ocurrir, reafirmándose, de esta manera, el valor de la vida, la dignidad humana, la justicia, la libertad, la aceptación de las diferencias, la participación y la democracia. Es desde este enfoque que se afirma una comprensión más exigente y abarcadora de la democracia; una comprensión que no se resigna a entenderla como mero equilibrio institucional, sino que demanda de ella una genuina experiencia de ciudadanía para la sociedad. Es decir, una experiencia de inclusión, de ejercicio real de los derechos y de respeto por parte del Estado y de la sociedad.

Un elemento central de tal exigencia es, obviamente, el cumplimiento de la deuda de justicia con aquel que en el pasado fue víctima de violaciones de derechos humanos, teniendo sus derechos fundamentales afectados por la acción del Estado o de organizaciones no estatales (Reátegui, 2011, p. 36). 
De esta manera, los ejercicios de memoria histórica no solo forman parte de un capital social y simbólico de los ciudadanos, sino que además estimulan la necesidad urgente de nuevas miradas, estrategias y acciones históricas. El ejercicio del derecho de los pueblos a la memoria, a construir un espacio en el que los diferentes grupos y personas puedan recrear y elaborar con libertad su pasado, debe ser garantizado por el Estado.

El derecho a conocer y valorar críticamente las memorias militantes y la historia de las organizaciones políticas que en diferentes etapas de la historia del país, especialmente en los periodos de dictadura militar, buscaron la transformación social haciendo hincapié en la justicia, en la igualdad y en la participación, y resistieron con los medios que les fue posible las violaciones de los derechos humanos cometidas por el Estado, es otra dimensión importante de la educación para el nunca más. De igual forma, el combate al terrorismo de Estado como forma política de negar el conflicto, de borrar e invisibilizar las diferencias, de disciplinar autoritariamente a la sociedad e imponer el método de las desapariciones -instrumento utilizado sobre todo durante la dictadura militar y en los gobiernos dictatoriales-, traducidos en la violación sistemática de los derechos humanos de la población. También constituye otra dimensión la demanda irrenunciable a la verdad, a la justicia y a la reparación debida, para que los responsables civiles, políticos, administrativos y penales de los crímenes (asesinatos, desapariciones, torturas, prisiones) que se cometieron durante la dictadura, sean investigados, llevados a juicio y castigados política y penalmente.

Una dimensión fundamental de la educación para el nunca más articulada con la memoria, es su posibilidad de contribuir al intercambio y al diálogo entre las diferentes generaciones; entre aquellas que vivieron aquel periodo y los jóvenes que nacieron posteriormente. Dicha interacción permite que se conozca el pasado reciente, así como las diferentes visiones y proyectos de sociedad que estaban en disputa en aquel momento histórico, y, por otra parte, contribuye a recrear nuevos horizontes emancipatorios para la construcción de la sociedad actual.
Además, ayuda a revelar que el pasado más próximo y el más remoto, así como el presente, no solo se construyen, sino que fueron construidos a partir de la lucha de diferentes proyectos y visiones de la sociedad en conflicto y en la tensión entre las diferencias, las desigualdades y las luchas económicas, sociales, políticas, étnicas, culturales, de género y orientación sexual de los diferentes grupos y sectores sociales.

Educar para el nunca más contribuye también a la construcción, afirmación y al empoderamiento de las identidades de los diferentes grupos y movimientos sociales, especialmente de los discriminados y subalternizados. Los fortalece como sujetos de derechos $\mathrm{y}$ actores sociales y ayuda a visibilizar y reconocer el aporte de sus luchas para la construcción de la democracia y de la justicia social, económica, cultural y política.

Por fin, la educación para el nunca más colabora para el enfrentamiento y la denuncia de todas las prácticas del Estado que, en el presente, hieren o limitan los derechos individuales y colectivos, así como sus posibilidades de expresión y su ejercicio.

Educar para el nunca más es afirmar un proyecto de construcción democrática que reconoce los derechos de todos los ciudadanos, sobre todo de aquellos que pertenecen a los grupos sociales discriminados e invisibilizados, a participar, disputar y proponer nuevas formas de convivencia y construcción social que garanticen la aplicación de los derechos para toda la sociedad, como condición para que nunca más haya opresión y terrorismo de Estado.

\section{Pedagogía de la memoria y educación para el nunca más}

Para articular pedagógicamente la educación para el nunca más y la memoria, es de vital importancia tener en cuenta el modo como se indaga el pasado a partir del presente. Es decir, qué recordar, cómo recordar y para qué recordar. El papel de los educadores a la hora de trabajar el pasado reciente en la escuela es fundamental, ya que, además de poseer un conocimiento específico sobre el tema, ellos también son sujetos de derechos, por lo que tienen el desa- 
fío de estimular los cuestionamientos, de tal modo, que la pedagogía de la memoria adquiera vínculos significativos con el pasado y permita imaginar y construir futuros más justos.

Como nos recuerda Eduardo Galeano: "Hacer memoria no es memorizar. Hacer memoria es pensarse, ubicarse, inscribirse en un caminar como pueblo, colectivo múltiple y diverso, que hace historia'. Por ello mismo, resulta necesario recoger el legado de quienes en otra época estuvieron en las mismas calles. Travesías de tiempo somos" (Amorim, 2014, p. 4).

El trabajo con nuestro pasado reciente puede también transformarse en un puente que interpreta la propia experiencia, es decir, que puede decirnos de qué manera podemos participar como un(a) ciudadano(a) activo(a) y responsable, cómo no ser indiferente al dolor y al sufrimiento de las personas o grupos, cómo exigir que las sociedades y los gobiernos respeten y hagan efectivos los derechos humanos para todos.

En ese sentido, en los últimos años, en varios países de América Latina las políticas públicas modificaron los currículos por medio de nuevas legislaciones que pasaron a exigir la incorporación de contenidos y el estudio del pasado reciente -especialmente en aquellos países donde se vivieron experiencias duras y sangrientas de dictadura militar- con el fin de promover la educación para el nunca más.

De esta manera, en la última década se han desarrollado especialmente diferentes formas y espacios que ayudan a ahondar en la memoria, tales como: museos, lugares de la memoria, recordación de fechas, películas, canciones y diferentes manifestaciones culturales que visibilizan y colaboran con el trabajo pedagógico. Algunas visiones llegan a identificar una especie de inflación de la memoria. Más allá de esta interpretación, es importante considerar esta expansión como una respuesta a uno de los problemas de la cultura contemporánea neoliberal, que es silenciar el pasado, entendido este como un peso que se lleva a cuestas, y no, en cambio, como una corriente de vida, importante para que se construyan sentidos para una vida más plena.
Consideramos que una educación en derechos humanos que articule la memoria para el nunca más debe llevarse a cabo teniéndose en cuenta cuatro ejes pedagógicos:

- Vínculo pasado-presente: consiste en relacionar la experiencia histórica, especialmente la de las violaciones de los derechos humanos, con problemáticas actuales de la sociedad, que tienen que ver con el respeto y la promoción de los derechos humanos.

- Desarrollo de una memoria crítica: valorar el ejercicio de recordar y de hacer memoria como una forma válida de construir conocimiento social. Aproximarse al tema partiendo de las historias de vida de los sujetos, construyendo una visión colectiva desde una visión individual, desde la sensibilidad, una dimensión más intelectual.

- Construcción de un pensamiento reflexivo y crítico: estimula la autonomía y la responsabilidad personal como un sujeto activo que se posiciona y contribuye en la construcción de una sociedad justa, pacífica, inclusiva y democrática.

- Promoción de una cultura de los derechos humanos: la educación en derechos humanos es una mediación importante para la construcción democrática. Incluye el reconocimiento y el respeto hacia el otro, el desarrollo de una ciudadanía activa y participativa y la desconstrucción de todas las actitudes y prácticas autoritarias y colonizadoras.

Para educar para el nunca más las profundizaciones desde la memoria ponen en cuestión los principios de verdad establecidos tanto desde el imperativo ético, como desde un acercamiento que posibilite colocar a los sujetos en una relación dialógica que a través de la experiencia permita unir ética, política y conocimientos a partir de una mirada crítica. Se recuerda con los otros. El contenido de lo que se recuerda pasa por la experiencia y se guía por el principio de justicia. Actúa como memoria viva, construida cada vez que se dialoga y se reflexiona con los otros. Como afirma Le Goff 
(1992), "la memoria en la que crece la historia, y que a su vez la alimenta, busca salvar el pasado para servir al presente y al futuro. Debemos trabajar de manera tal que la memoria colectiva sirva para la liberación y no para la esclavitud de los hombres" (p. 477).

\section{Propuestas pedagógicas para educar para el nunca más}

Como desarrollamos hasta aquí los aspectos más importantes para una pedagogía de la memoria que contribuya para la educación para el nunca más, presentamos enseguida tres propuestas pedagógicas elaboradas por el equipo que coordinamos en la organización no gubernamental Novamérica, inspiradas en la (des)conmemoración del cincuentenario del golpe civil-militar, deconstruyendo la idea de historia y memoria como un pasado cristalizado y reconociendo, dentro de la pluralidad de proyectos en disputa del pasado, a aquellos que fueron vencedores y vencidos. Además, se busca identificar cuánto de ese pasado aún está presente en nuestros días y en las propuestas y proyectos actuales de construcción democrática (Pedreira, 2014, p. 4).

La primera es una plataforma virtual: el Observatorio de Educación en Derechos Humanos en $\mathrm{FocO}^{2}$, un espacio de información, profundización y discusión sobre perspectivas teóricas, políticas públicas y prácticas en el ámbito de la educación en derechos humanos. Su principal finalidad es constituirse en un ambiente en el que sea posible el diálogo entre diferentes abordajes sobre el tema y en el que se establezca un intercambio creativo y productivo.

Las diferentes posibilidades de abordaje que presenta están dadas por los íconos de navegación, especialmente el de pedagogía de la memoria y de material pedagógico, en los que se encuentran diferentes tipos de materiales para trabajar el tema tanto en la formación continuada de educadores, como con los(as) alumnos(as) en la escuela, además de múltiples accesos para instituciones referidas al trabajo de la memoria y centros de memoria. Tam-

2 www.observatorioedhemfoco.com.br bién en el Observatorio se encuentran referencias y materiales para la educación en derechos humanos en los otros íconos correspondientes a multimedia, legislación, biblioteca, noticias, presentación, agenda y enlaces.

El Observatorio es una estrategia virtual utilizada por Novamérica para la formación continuada de educadores que, al hacerla disponible en Internet, se socializa con otros grupos, instituciones, movimientos y personas que tengan interés en su aprovechamiento. También es un espacio que contribuye al trabajo de investigación y académico en el área de la educación en derechos humanos que recoge producciones de Brasil y de América Latina, que en muchos casos no son de fácil circulación y acceso.

El Observatorio se articula con el Movimiento de Educadores en Derechos Humanos (MEDH) y con el Movimiento Socioeducativo Educar en Tiempos Difíciles (MSE), de carácter latinoamericano. Cuenta con la colaboración del Grupo de Estudios sobre Cotidiano, Educación y Cultura(s) (GECEC) vinculado al Departamento de Educación de la PUC-Río de Janeiro.

La segunda propuesta es un ciclo de talleres pedagógicos destinado a la formación de maestros, con el título de Hacer memoria, tejer ciudadanía, fortalecer identidades. A partir de la educación para el nunca más, articula, como ya nos referimos anteriormente, estas dimensiones de la educación en derechos humanos necesarias para la construcción democrática.

A los cincuenta años del golpe civil-militar que dio inicio al periodo de más de veinte años de dictadura, volvemos la mirada hacia la historia reciente, y con ello, volvemos a preguntarnos sobre la conformación de nuestro presente y de nuestra democracia. Medios de comunicación, universidades, políticos y agentes culturales se enmarcan en un debate nacional que tiene como principal objetivo repensar nuestra historia colectiva para hacer frente a los imperativos de nuestro tiempo actual.

El ciclo desarrolla cuatro talleres pedagógicos de tres horas de duración cada uno. Entendemos el taller pedagógico como un espacio de construc- 
ción colectiva de saberes, de análisis de la realidad y de ejercicio de los derechos humanos. Es un espacio también de intercambio y de contraste de experiencias desarrolladas por los maestros con sus estudiantes. La metodología utilizada promueve la participación, la socialización de la palabra y de los conocimientos, la vivencia de situaciones concretas y el compromiso con la transformación de la realidad. Esta metodología también contribuye a reforzar el sentido crítico, la dimensión ética y sociopolítica inherentes a la lucha por la ciudadanía y para la educación en derechos humanos (Candau et al, 2013, p. 162). Por razones de espacio presentamos a continuación un resumen de cada taller, el desarrollo completo puede ser encontrado en la página del Observatorio de Educación en Derechos Humanos en Foco indicada anteriormente.

El primer taller se titula "Recordar es vivir". Sus objetivos son: ahondar en los diferentes sentidos del concepto de memoria y en sus relaciones con la vida personal y colectiva; y establecer conexiones entre memoria, olvido e identidades.

Desarrollamos los siguientes dispositivos pedagógicos: discusión sobre los sentidos de la memoria a partir de objetos e imágenes que son evocadores. Correlación entre memoria personal y colectiva basada en la línea de tiempo de los acontecimientos históricos recientes. Reconstrucción histórica a través de la oralidad y de la experiencia personal. Exposición fotográfica sobre el golpe de Estado y el regreso a la democracia en un contraste visual. Aproximación afectiva y análisis de letras de música de resistencia producidas por los artistas durante el periodo de dictadura. Este último aspecto es transversal en los cuatro talleres.

El segundo taller es sobre "1964: marcas de la memoria, lecciones de la historia"', con los siguientes objetivos: hacer memoria de las violaciones de

31964 se refiere al año de inicio del periodo de dictadura en la que los militares gobernaron Brasil. El Golpe civil-militar se produjo el 1 de abril de 1964 con la derrocada del presidente João Goulart. Por las características de este período de dictadura hay diferentes enfoques históricos en relación con las fechas de su inicio y finalización. Asumimos la perspectiva que considera su finalización con la elección de Tancredo Neves para presidente el 15 de enero de 1985. derechos humanos vividas durante el periodo de la dictadura militar; y percibir la importancia de la memoria en la construcción de una cultura de los derechos humanos y de la democracia como estilo de vida.

Este taller tiene los siguientes dispositivos pedagógicos: a) discusión de documentarios y películas sobre las violaciones y las diferentes miradas acerca de la dictadura civil-militar; b) aproximación, interpretación y vivencia a partir del testimonio de las víctimas de los que sufrieron torturas, especialmente las mujeres, de los que tuvieron que partir para el exilio y de la resistencia cultural expresada a través de la poesía y de las músicas de protesta de la época; y c) las lecciones de la historia que podemos recoger actualmente de todas esas experiencias para afirmar los derechos humanos y construir la democracia.

El tercer taller se titula "Ciudadanía: ¿derechos o consumo?" y sus objetivos son: identificar los diferentes sentidos del concepto de ciudadanía y la importancia de la participación social en la lucha por los derechos; y reconocer la centralidad del mercado en las prácticas sociales y sus contradicciones en la afirmación de la ciudadanía.

Sus dispositivos pedagógicos son: a) identificación a través de la experiencia y de los conceptos de los diferentes tipos de ciudadanía, de sus avances especialmente en el periodo de democratización y de los límites actuales; b) denuncia de los derechos que el mercado transformó en mercadería y en objeto de consumo, especialmente los derechos sociales; c) reconocimiento de los gritos de lucha de los diferentes movimientos sociales por los derechos que todavía no son plenamente efectivos en la construcción de la ciudadanía actual y por los que todavía hay que seguir luchando para mejorar la calidad de nuestra democracia; y d) discusión de video y de texto sobre consumo: "Ciudadanía y niñez: ¿una ecuación posible?”.

La época de la dictadura está marcada por el uso de varios recursos jurídicos denominados Actos Institucionales que colocaron en práctica la censura, la persecución política, la supresión de los derechos constitucionales, la falta total de democracia, la tortura y la represión de los que eran contrarios al régimen militar. 
El cuarto taller, último del ciclo, es sobre "Fortalecer identidades, educar para el nunca más”, con los siguientes objetivos: a) conocer el significado de educar para el nunca más desde la perspectiva de la educación en derechos humanos; $y b$ ) proponer actividades/proyectos pedagógicos que contribuyan al fortalecimiento de las identidades subalternizadas y al enfrentamiento de prejuicios y discriminaciones sociales.

Tiene los siguientes dispositivos pedagógicos: a) aproximación visual e histórica del origen del nunca más en el Cono Sur; b) apropiación de los ejes pedagógicos de educación para el nunca más; y c) elaboración en grupo de actividades o proyectos que tengan como eje la vinculación del pasado/presente y la promoción de una cultura de los derechos humanos para desarrollar en la escuela.

La tercera propuesta se relaciona con la anterior y focaliza actividades para que el maestro desarrolle en clase. Realizamos la selección a partir de nuestra publicación bimestral, el boletín DD.HH. en la clase, una publicación de apoyo pedagógico que presenta sugerencias prácticas para el trabajo de educación en derechos humanos, divulga actividades desarrolladas por los educadores en las escuelas y ofrece subsidios teóricos que apoyen la práctica cotidiana. Está estructurado de forma que permita reforzar los temas abordados en el ciclo de talleres pedagógicos para los educadores, siendo una mediación importante que contribuye y apoya la inserción y el debate del tema dentro de la escuela. En ese sentido, durante este año la publicación tiene también como referencia el lema "Hacer memoria, tejer ciudadanía, fortalecer identidades". Las diferentes articulaciones y aproximaciones entre memoria, ciudadanía e identidades se entienden y se presentan como la posibilidad del educador de abrir ventanas para la formación de sujetos que puedan comprender y actuar en el mundo de forma solidaria y consciente. Las cuatro actividades aquí seleccionadas están dirigidas al ciclo de enseñanza fundamental para octavo y noveno año, las presentamos a continuación.

Primera actividad "Derechos a la memoria y a la verdad": focaliza el trabajo con el concepto de memoria, su aproximación a las historias de vida y su importancia para la construcción de las identidades individuales y sociales. Se apoya en el conocimiento del derecho a la memoria y a la verdad destacando que en los últimos treinta años, en América del Sur, Argentina, Chile, Paraguay y Uruguay crearon Comisiones de la Verdad que en muchos casos sirvieron para denunciar y mostrar graves violaciones a los derechos humanos ocurridas durante los periodos de dictadura civil-militar en estos países. En Brasil, recién fue posible instalar la Comisión de la Verdad el 16 de mayo de 2012, creada por la Ley12.528/2011 para hacer efectivo el derecho a la memoria y a la verdad histórica sobre las graves violaciones a los derechos humanos ocurridas entre el 18 de septiembre de 1946 y el 5 de octubre de 1988, en especial en el periodo de la dictadura civil-militar (1964-1985).

- Dialogar sobre la importancia de la historia de vida personal y colectiva. Hacer un resumen de lo que los alumnos entienden por memoria/ olvido. Preguntas que pueden ayudar: ¿Qué memorias nos hacen sentir bien? ¿Qué memorias nos gustaría evitar? ¿Es posible recordar todo lo que vimos, sentimos y oímos? ¿Recordamos las cosas siempre de la misma manera o nuestras memorias cambian? ¿Conocen a alguien que haya perdido la memoria? ¿Qué sucedió con ella?

- Poner una música suave y pedirles a los alumnos que busquen en su memoria hechos importantes de su vida que les hayan dado felicidad, tristeza o rabia. Pedir que escriban en pocas líneas dicha historia.

- A continuación, pedirles que recuerden hechos importantes que hayan ocurrido en su comunidad y que hayan cambiado la vida de las personas. Pedir que escriban en pocas líneas esa historia.

- Organizar grupos para que los alumnos compartan sus escritos.

- Una vez compartidas las historias, cada grupo deberá hacer una representación a partir de una de ellas o de partes de varias, y presentarla a los compañeros. 
Pedagogía de la memoria y educación para el "nunca más" para la construcción de la democracia

Susana Sacavino

- Teniendo en cuenta el trabajo realizado por cada grupo, el maestro promoverá la reflexión sobre la importancia de la dimensión individual y colectiva de la memoria para las historias de vida.

- Terminar con la presentación y los comentarios en torno al dicho "Umuntu Ngumuntu Ngabantu”, de la cultura zulu - pueblo de África del Sur- que significa: "Una persona es una persona por intermedio de las otras personas".

- Como desdoblamiento de esta actividad, el profesor puede proponer una visita a un museo, a un centro de la memoria o a un hogar de ancianos. De manera más amplia, la actividad puede desencadenar el deseo de recolectar las memorias de la comunidad por medio de la identificación de lugares de la memoria o de entrevistas que cuenten historias de vida y memorias de la escuela, del barrio o del municipio.

Segunda actividad "Relación entre memoria, historia y derechos humanos": conceptos claves para tejer ciudadanías críticas y participativas. Aunque son fundamentales para la formación de una consciencia crítica y democrática, la relación entre tales conceptos, en general, es poco discutida en la escuela. Hacer memoria de las violaciones de los derechos humanos y contar la historia desde el punto de vista de los grupos y culturas subalternizados, no son tareas fáciles, tampoco comunes. Un ejemplo es la dificultad de hacer efectiva la inclusión de la historia y de la cultura afrobrasileña e indígena en los currículos escolares (Ley 10.639/2003 y Ley $11.645 / 2008)$ y la casi inexistencia de la narrativa de víctimas de regímenes de dictadura militar en los libros didácticos de historia. Prácticas sociales autoritarias, discriminadoras y racistas son temas polémicos e importantes para la educación para el nunca más que nos desafían política, ética y pedagógicamente en el cotidiano. La educación en derechos humanos es fundamental para visibilizar y transformar esa realidad.

- Para trabajar las memorias y la historia de las violaciones y luchas por los derechos humanos, utilizamos la versión digital del libro Brasil: dictadura militar. Un libro para los que nacieron mucho después..., de Joana D’Arc F. Ferraz y Elaine de A. Bortone, disponible en: www. observatorioedhemfoco.com.br

- Hacer una breve presentación de las ideas centrales del libro, destacando la tapa y la dedicatoria. Por tratarse de una publicación HQ, y en formato electrónico, los alumnos se mostrarán interesados en participar.

- Conversar libremente sobre la relación entre memoria, historia y derechos humanos. Identificar qué es lo que los alumnos saben sobre derechos humanos, sobre la importancia de defenderlos y sobre las situaciones de negación $\mathrm{y}$ de violaciones de esos derechos.

- Hacer la lectura colectiva de la obra utilizando algunos fragmentos de la historieta. Sugerimos, en orden, las siguientes páginas: $7,12,13$, $15,18,19,10,23,11 \mathrm{y}$, para terminar, las páginas 24,25 y 26 . En caso de que la escuela tenga laboratorio de informática, la lectura de este libro será un buen momento para utilizarlo.

- Observación: queda a criterio del educador seguir ese orden o hacer una lectura secuencial. Lo importante es que la lectura sea colectiva y que durante la misma los alumnos se sientan involucrados con la historia y con sus personajes.

- Después de la lectura y del debate en torno a las situaciones que presenta el libro, proponerles que en grupo realicen con el celular un breve video sobre las memorias del periodo de la dictadura militar y sobre las luchas por la democratización de Brasil. La idea es que los grupos partan de una pregunta corta y directa para que el entrevistado también pueda ser breve. Funcionarios del colegio, familiares y personas del barrio son posibles candidatos. ¿Cuáles son las memorias de la dictadura militar y de los años de transición democrática? ¿Qué hechos marcaron aquel momento histórico? La actividad se puede realizar en el horario del recreo, a la hora de la salida o en casa. Hacer hincapié en la necesidad de que cada grupo debe estar bien preparado para hacer el trabajo. 
- Cada grupo presentará el video a sus compañeros. El educador deberá señalar las convergencias y las diferencias entre los testimonios. Subrayar la importancia de romper con los silencios y con los olvidos en relación a las graves violaciones a los derechos humanos. Destacar que dicho ejercicio se debió a la necesidad de rescatar memorias/olvidos sobre hechos determinados y que la historia se escribe a partir de la contextualización, del análisis, de la interpretación de los relatos, así como de otras fuentes históricas.

- En caso de que sea deseo de todos, y luego de pedirles autorización a los entrevistados y a los educadores, pueden publicarse los videos en una fan page del grupo o individual para profundizar y actualizarse sobre el tema de la violación y la lucha por los derechos humanos con base en hechos recientes.

Tercera actividad "Tejer la ciudadanía, fortalecer la democracia": reafirmar el compromiso con una ciudadanía crítica y participativa es importante para la construcción de la democracia. Este año de 2014, además de (des)conmemorar los cincuenta años de la dictadura civil-militar en el marco de la memoria plural e irrestricta que apela a otros conceptos, para educar para el nunca más y afirmar los derechos humanos para todos los ciudadanos y ciudadanas, tenemos también elecciones presidenciales y para el poder legislativo. En el día tras día del país están presentes las campañas electorales, con la baja credibilidad de gran parte de la población en los políticos por no sentirse representados, pero también las luchas por la conquista de derechos y de otras formas de participación. Reflexionar de manera crítica sobre la ciudadanía actual tejida y fuertemente influenciada por la lógica del mercado que transforma las personas y los derechos en mercadería es importante para calificar la democracia.

Aprovechando el año electoral, esta actividad es para reflexionar sobre los usos y los abusos del marketing político y sobre los efectos que causa. Realizar la misma servirá también como un ejercicio de ciudadanía.
- Dividir el curso en grupos y a cada uno distribuirle hojas blancas, revistas, bolígrafos, marcadores, pegamento y tijera para que hagan el afiche de campaña de un candidato inventado por ellos.

- El objetivo es que hagan una campaña política basándose en el impacto visual. Por eso, el educador deberá subrayar la importancia de saber elegir los elementos utilizados para hacer el afiche, a saber: la postura, las características físicas, la expresión, la ropa del candidato, los símbolos, los logos, los eslogans, los colores, etc.

- Una vez hechos los afiches, cada grupo deberá presentarlo al resto del curso y explicar el porqué de ciertas elecciones al hacer la propaganda del candidato. Comparar las decisiones tomadas por los alumnos con la propaganda electoral que se divulga en los medios.

- Luego de la presentación, destacar las convergencias y las diferencias en las decisiones tomadas por los grupos, y debatir sobre la influencia de la publicidad en la toma de nuestras propias opciones. Preguntarles a los alumnos si ya compraron algún producto a causa de la propaganda y sobre los recursos y estrategias de seducción de que se sirve la publicidad. Indagar sobre los riesgos del abuso del marketing político para la práctica de la ciudadanía.

- Para terminar, pedirles que peguen los afiches de los candidatos por las paredes de la escuela, con un cartel abajo que diga: " $i$ Candidato o producto?”. “¿Consumidor o elector?”.

- Como desdoblamiento, solicitarles que organicen actividades que sirvan de estímulo, en la comunidad escolar, para discutir sobre cómo los políticos son tratados como un producto de consumo en las campañas electorales. La idea es que dichas actividades contribuyan al ejercicio de una ciudadanía crítica y participativa.

Cuarta actividad "Fortalecer identidades, educar para el nunca más": dimensiones fundamentales de la educación en derechos humanos, con foco en la valorización de la diversidad cultural y en la recu- 
peración de la memoria de identidades histórica y culturalmente silenciadas. En ese sentido, memoria e historia se interrelacionan, la historia representa la conquista de un grupo social de su pasado colectivo, pero también un instrumento y una mediación de poder. Educar para el nunca más significa deconstruir la cultura del silencio y de la impunidad presente en la mayoría de los países latinoamericanos, para formar para el cambio, la participación, la transformación y la construcción de sociedades verdaderamente democráticas, humanas, justas y solidarias.

Basándose en la pedagogía de la memoria, esta actividad busca afirmar el nunca más desde una perspectiva de los derechos humanos.

- Hacer un afiche o escribir en el pizarrón la siguiente frase: "Hay hombres que luchan un día y son buenos. Hay otros que luchan un año y son mejores. Hay quienes luchan muchos años, y son muy buenos. Pero hay quienes luchan toda la vida, esos son los imprescindibles", del poeta alemán Bertolt Brecht.

- Después de leer la frase, incentivarlos para que digan qué piensan sobre ella, y preguntarles si conocen a personas o grupos que se correspondan con los señalados por el poeta. Orientar la charla y dar información sobre Bertolt Brecht. Preguntarles: ¿A qué luchas se refiere? ¿Quiénes son esos hombres y mujeres imprescindibles?

- Profundizar el debate solicitando o dando ejemplos de acontecimientos históricos que representan graves violaciones a los derechos humanos, tales como: la esclavitud, el genocidio de indígenas, el holocausto de los judíos, el apartheid, las dictaduras militares en América Latina, las masacres actuales en muchas ciudades, etc. Hacer lo mismo con personas y grupos que en un pasado reciente lucharon contra la violación de los derechos humanos: Gandhi; Nelson Mandela; Martin Luther King; Abdias do Nascimento; Sobral Pinto; Chico Mendes; Betinho; las Madres de Plaza de Mayo, en Argentina; las Madres de Acari, en Río de Janeiro; el Grupo Tortura Nunca Más, los que lucharon por la amnistía a los presos políticos de la década de 1970; la campaña de las Directas Yá, en 1984; los movimientos sociales por el derecho a la tierra, a la vivienda; etc. Pueden darse los ejemplos oralmente, pero sería interesante que se hiciera por medio de imágenes y de recortes de noticias distribuidas al curso.

- Pedirles a los alumnos que busquen información sobre las personas/grupos mencionados (o sobre otros grupos/personas) que lucharon o luchan por los derechos, y también sobre los instrumentos legales/instituciones que actualmente trabajan para defender y garantizar esos derechos en Brasil. Cada grupo hará una puesta en común sobre los resultados obtenidos en su investigación. Se sugiere que armen una cartelera con los hombres y mujeres imprescindibles.

- Luego de la presentación de los grupos, preguntarles: ¿Cuáles son las luchas por los derechos que ustedes consideran imprescindibles para que las violaciones cometidas en el pasado no se repitan en el Brasil de hoy?

- Con el objetivo de afirmar el nunca más y de evidenciar la importancia de hacer memoria sobre las luchas por los derechos para que las violaciones no se repitan, repartir la letra de la canción Pequeña memoria de un tiempo sin memoria, de Gonzaguinha, y cantar juntos, disponible en: www.observatorioedhemfoco.com.br

- Contextualizar la música con los movimientos de resistencia a la dictadura civil militar de Brasil. Pedirles que, espontáneamente, identifiquen los versos que consideren más significativos.

Para educar para el nunca más es importante mantener viva la memoria individual y colectiva que exige favorecer visiones críticas del pasado y sus realidades, pero también lúcidas y con capacidad de integración y saneamiento colectivo capaces de exigir justicia y movilizar energías de construcción de futuro y de consensos.

En la educación en derechos humanos no se puede ignorar u ocultar el pasado, porque si no se reconoce el pasado, no es posible construir el futuro 
ni ser sujeto activo en esa construcción. No se puede imponer el silencio a la memoria de un grupo (Sacavino, 2013, p. 88).

\section{Consideraciones finales}

Para finalizar este artículo que, de ningún modo pretende cerrar el camino que nos lleva a la articulación entre la educación para el nunca más y la(s) memoria(s), destacamos algunos puntos que consideramos importante reafirmar esperando no ser redundantes. En los procesos educativos no es suficiente con solo recordar, es necesario reflexionar teniendo en cuenta que cada persona lleva consigo muchas historias y memorias construidas a través de diferentes percepciones y experiencias. Recomendamos que la aproximación a los temas sea gradual integrando diferentes dimensiones, individual, colectiva, afectiva, cognitiva.

De la misma manera que en la educación en derechos humanos afirmamos el reconocimiento de la dignidad humana y el derecho a la vida como fundamentales, debemos conocer y reconocer los errores del pasado para intentar evitar que se repitan en el futuro. En ese sentido, memoria, historia y derechos humanos son conceptos íntimamente relacionados e importantes para la construcción de las sociedades y las democracias actuales. Así lo expresa Ricardo Lagos:

Muchos creyeron que para superar los traumas del pasado era suficiente dar vuelta la página o echarle tierra a la memoria. Una sociedad no se hace más humana negando el dolor, el dolor de su historia; por el contrario, lo único que se consigue con eso es ofender y crear sufrimiento. [...] No hay futuro sin pasado (López, 2006, p. 16).

Finalmente, consideramos importante recordar que la lucha por el sentido del pasado se da en función de la lucha política presente y los proyectos de futuro democráticos. Como destaca Jelin (2005, p. 226), cuando se plantea de forma colectiva, como memoria histórica o como tradición, como proceso de conformación de la cultura y de búsqueda de las raíces de la identidad, el espacio de la memoria se transforma en un espacio de lucha política.

\section{Referencias bibliográficas}

Berro, A., Juanicó, G. y Puente, C. (2010). Educando en la memoria. Guía pedagógica para el trabajo en el aula. Montevideo: Dirección de Derechos Humanos del Consejo Directivo Central de la Administración Nacional de Educación Pública.

Candau, V.M. (2005). Educação em direitos humanos: principais desafios. Mimeografiado. Río de Janeiro.

Candau, V.M. (2013). Educação em Direitos Humanos e formação de professores(as). Sao Paulo: Cortez Editora.

Etxeberria, X. (2013). La construcción de la memoria social: el lugar de las víctimas. Santiago de Chile: Museo de la Memoria y de los Derechos Humanos.

González, E. (2011). Até onde vão as comissões da verdade? En: F. Reátegui (org.). Justiça de Transição. Manual para a América Latina. Brasilia: Comissão de Anistia do Ministério da Justiça, pp. 339-356.

Jelin, E. (2004). Fechas de La memoria social. Las conmemoraciones en perspectiva comparada. Íconos, $18,141-151$.

Jelin, E. (2005). Exclusión, memorias y luchas políticas. En: D. Mato (org.). Cultura, política y sociedad. Perspectivas latinoamericanas. Buenos Aires: Clacso, pp. 219-239.

Lagos, R. (2004). Para nunca más vivirlo, nunca más negarlo. CEME. Archivo Chile. Recuperado el 8 de octubre de 2014 de: http://www.archivochile.com/ Derechos_humanos/com_valech/gob_otros_estado/ hhddgobotros0020.pdf

Le Goff, J. (1992). História e Memória. Campinas: UNICAMP.

López, N.D.Z. (2006). La memoria justa, una fenomenología de la memoria histórica en P. Ricoeur. Santiago de Chile. Recuperado el 16 de mayo de 2012 de: http:// www.corredordelasideas.org/docs/ix_encuentro/ nilo_zarate.pdf

Novamérica (2014). Direitos Humanos na Sala de Aula. No. 127, 128, 129, 130. Río de Janeiro: Novamérica.

Pedreira, S. (2014). Marcas do que se foi, sonhos que vamos ter... Direitos Humanos na Sala de Aula, 128. Río de Janeiro: Novamérica.

Peña, C. (2013). Tejer la memoria hacia las nuevas generaciones. En: S. Stern. Memorias en construcción: los retos del pasado presente en Chile, 1989-2011. Santiago de Chile: Museo de la Memoria y de los Derechos Humanos. 
Reátegui, F. (org.). (2011). Justiça de Transição. Manual para a América Latina. Brasilia: Comissão de Anistia do Ministério da Justiça.

Rubio, G. (2007). Educación y Memoria. Desafíos y tensiones de una propuesta. Nómadas. Revista Crítica de Ciencias Sociales y Jurídicas 15, 163-175,

Sacavino, S. (2000). Educação em Direitos Humanos e Democracia. In: V. Candau y S. Sacavino (org). Educar em direitos humanos. Construir democracia. Río de Janeiro: DP\&A, pp. 36-48.

Sacavino, S. (org.) (2013). Educación en Derechos Humanos. Pedagogías desde el Sur. Río de Janeiro: Novamérica - Apoena.

Servicio Paz y Justicia (SERPAJ) (1989).Uruguay Nunca Más. Informe sobre la violación a los derechos humanos (1972-1985). Montevideo. Recuperado el 12 de octubre de 2014 de: http://www.memoriaenelmercosur.educ.ar/indexbe3b.html? $\mathrm{p}=145$

Stern, S. (2013). Memorias en construcción: los retos del pasado presente en Chile, 1989-2011. Santiago de Chile: Museo de la Memoria y de los Derechos Humanos.

Tizon, H. (2012). Memorial de la Puna. Buenos Aires: Alfaguara.

Todorov, T. (2013). Los usos de la memoria. Santiago de Chile: Museo de la Memoria y de los Derechos Humanos.

Torres, A. (2014). Hacer historia desde Abajo y desde el Sur. Bogotá: Ediciones Desde Abajo. 